\title{
Identificando e corrigindo erros de processamento em seções de resistividade elétrica de solos
}

Daniel F. S. Maia, Guilherme P. Castilho

Brain Tecnologia

danielmaia@braintecnologia.com.br

Copyright 2006, SBGf - Sociedade Brasileira de Geofísica

Este texto foi preparado para a apresentação no II Simpósio de Geofísica da Sociedade Brasileira de Geofísica, Natal, 21-23 de setembro de 2006. Seu conteúdo foi revisado pela Comissão Tecno-científica do II SR-SBGf mas não necessariamente representa a opinião da SBGf ou de seus associados. E proibida a reprodução total ou parcial deste material para propósitos comerciais sem prévia autorização da SBGf.

\section{Resumo}

A interpretação equivocada de seções de resistividade elétrica do solo pode acarretar enormes prejuízos para a empresa que utilizou tal resultado. Mesmo com uma aquisição bem planejada e executada, o intérprete pode ser enganado por um processamento mal-feito. A habilidade de identificar tais erros é, portanto, imprescindível ao geólogo/geofísico que trabalha com a interpretação destes dados.

Este trabalho traz algumas evidências de problemas de processamento, assim como sugestões para corrigi-los.

\section{Introdução}

Atualmente, quando se trata da necessidade de se fazer uma investigação indireta cuidadosa da subsuperfície mantendo os baixos custos, o Caminhamento Elétrico Multi-eletrodos (CEME) 2D é a melhor opção [Dahlin, 1996]. O método baseia-se na injeção de corrente no solo e na medida simultânea dos potenciais gerados em diferentes pontos da superfície [Griffths and Barker, 1993] [Barker, 1978]. Através destas medidas de corrente e potencial, realiza-se um processo conhecido como inversão para obter-se um modelo de resistividade da subsuperfície [Lines and Treitel 1985] .

Sabe-se que a escolha equivocada do arranjo e do protocolo de aquisição pode influenciar negativamente a qualidade de uma seção. Como as maiores dificuldades são encontradas quando o dado original não é da melhor qualidade, começaremos tratando um dado cuja aquisição foi insuficiente.

\section{Metodologia}

De forma a deixar mais claro o desenvolvimento deste trabalho, optou-se pela utilização de um modelo teórico (Figura 1a). Desta forma, será possível avaliar o quanto o resultado da inversão se aproxima do esperado. A modelagem foi feita utilizando-se o software Res $2 \mathrm{dmod} \cap$ e a inversão o Res 2 dinv ${ }^{\circledR}$, ambos produzidos pela Geoelectrical Inc.
O modelo adotado tenta simular uma superfície com calçamento, de espessura ligeiramente maior em um dos lados, com base e sub-base compostas por um material mais condutivo, contendo um lençol freático salobro raso. Adicionalmente, existem no modelo dois detalhes importantes, um duto condutivo cortando perpendicularmente o meio da seção, e uma falha do "calçamento" a um metro da extremidade final da mesma.

Para simular uma situação onde a qualidade dos dados não é muito boa, utilizamos o protocolo dipolo-dipolo com $\mathrm{a}=2$ e $\mathrm{n}=4$, o que gera uma quantidade pequena de datum points e um imageamento raso. Introduzimos também um ruído induzido de $1 \%$. No fim compararemos o resultado com um dado com o dobro de pontos $(a=4)$ e o mesmo nível de ruído.

\section{Sinais de um resultado não confiável}

A evidência mais clara de um resultado não confiável é o erro R.M.S (root-mean-square). Ele representa a discrepância entre as medidas de potencial feitas pelo equipamento e as simulações de potencial (forward modeling) baseadas no modelo resistividade proposto [Dey and Morrison, 1979].

Normalmente um erro R.M.S. de $10 \%$ é considerado aceitável, mas veremos que já é preciso cuidado ao analisar um dado com essa convergência. Instabilidades no processo iterativo podem produzir valores muito altos (ou baixos) de resistividade nas bordas da seção ou na superfície. Normalmente as instabilidades causam oscilações de resistividade facilmente notáveis na superfície e nos níveis mais profundos da seção (Figura 4). O aparecimento destes artefatos é muito comum, e às vezes até inevitável, podendo ocorrer mesmo em uma linha com erro R.M.S. bem baixo.

Outra distorção comum é causada pela penetração de eletrodos em uma linha rasa. O modelo de inversão considera injeções puntuais de corrente, mas na realidade o eletrodo penetra no solo e emite corrente por toda a extensão enterrada. Isso se manifesta na seção como reentrâncias de resistividades anômalas na superfície. Esse efeito não pode ser evitado uma vez que, se o eletrodo não for bem fixado, problemas de acoplamento prejudicarão a medida.

Anomalias de superfícies caracterizam um problema muito sério para o processo de inversão. Como os blocos 
superficiais são os mais importantes para a resposta do modelo, toda a seção pode ficar comprometida

Cabe ao geólogo saber identificar estas discrepâncias para não ser induzido ao erro.

\section{Melhorando os resultados}

Aprimorar o processamento requer o conhecimento dos diversos parâmetros envolvidos no algoritmo de inversão. A matemática deste processo não será exposta neste trabalho mas pode ser facilmente encontrada na literatura [de Groot-Hedlin and Constable 1990] [Loke, 1994] [Loke, 2004].

Quando os primeiros algoritmos para inversão e forward modeling foram desenvolvidos, o tempo computacional era um problema muito sério e isso levou a maioria dos programadores a utilizar parâmetros não ideais, mas que dariam uma boa razão custo-benefício. Hoje, com máquinas bem mais poderosas, somos capazes de realizar um processamento muito mais fino sem que tenhamos que esperar horas por isso.

A figura 2 mostra o resultado da rotina de inversão utilizando-se todos os parâmetros em seus valores padrão. O processamento parou quando a diferença de ajuste entre duas iterações foi inferior a 5\%. O erro R.M.S. alcançado foi de $7.6 \%$, considerado bom, mas o duto foi representado por uma feição alongada verticalmente, característica em aquisições feitas com o arranjo dipolo-dipolo. Mostraremos adiante que estes alongamentos são mais do que um efeito do arranjo, uma evidência de processamento insuficiente.

A primeira coisa a se tentar é aumentar o número de iterações (Figura 3). Reduzindo-se a porcentagem de convergência entre iterações para $1 \%$ foi possível realizar mais 5 iterações. O erro R.M.S. caiu para 6\%, o duto começou a ficar mais bem definido, mas por outro lado um efeito de borda começou a gerar uma região altamente resistiva no canto inferior direito. Tais instabilidades serão tratadas mais adiante.

O segundo fator a se considerar é o tamanho dos blocos no modelo. Embora o padrão seja criá-los com largura igual à separação entre eletrodos, o resultado é sensivelmente melhor quando eles são criados com a metade deste valor, principalmente quando existem grandes variações de resistividade próximas à superfície. A figura 4 mostra a linha reprocessada com blocos mais estreitos, agora com um erro R.M.S. de 2.1\%. O duto já fica bastante visível, mas as instabilidades no nível inferior aumentaram e surgiram alguns valores espúrios na superfície.

Podemos melhorar ainda mais a resolução, definindo uma malha mais fina também para o forward modeling (simulação do potencial gerado pelo modelo de blocos proposto). Fazendo isso e utilizando 4 nós ao invés de dois em cada iteração de modelagem inversa, chegamos ao resultado apresentado na figura 5 . Como o número de variáveis cresceu, foi preciso mais iterações para alcançar a convergência de $1 \%$. O erro R.M.S. caiu para $1.53 \%$. Nota-se agora uma flutuação de resistividade na superfície, muito similar àquela causada pela penetração de eletrodos em linhas rasas. Oscilações de resistividade também aparecem na parte inferior da imagem.

A maior fonte de problemas neste imageamento elétrico é a falha no calçamento a um metro do final (vide figura 1). A camada mais superficial é a que mais influencia a medida, ou seja, apresenta a maior sensibilidade. Uma pequena alteração de resistividade nos blocos da superfície influencia a resposta do modelo como um todo. A falha tem uma resistividade 100 vezes menor do que os seus blocos vizinhos, caracterizando o que chamamos de anomalia de superfície; um problema sério em investigações elétricas.

A situação ainda apresenta dois fatores complicantes: o pequeno tamanho da falha e sua posição no final da linha. O tamanho da falha está no limite da resolução da aquisição e portanto de difícil modelagem. Além disso, os dados adquiridos nas bordas da linha são de baixíssima confiabilidade; apenas um ou dois datum points nesse caso.

Esses três fatores combinados geram um alto potencial de instabilidade em uma região cuja influência no modelo é bastante alta.

O primeiro passo para garantir a estabilidade é limitar a resistividade máxima e mínima permitida no modelo. Isso pode ser feito com um vínculo 'macio' que pode ser implementado mesmo quando não se conhece nada da geologia do terreno.

O damping factor, ou fator de Marquardt, restringe os valores da variação dos parâmetros; aumentá-lo ajuda a conter instabilidades.

Efeitos de borda podem ser amenizados reduzindo-se a influência dos blocos laterais no algoritmo de inversão.

O resultado deste conjunto de modificações é apresentado na figura 6 . Ao enrijecer os vínculos e inserir restrições, limitamos a liberdade para ajustes diminuindo a convergência final e o aumentando o erro R.M.S. para $4.5 \%$.

Neste caso, a redução da influência dos blocos laterais atrapalhou mais do que ajudou, fazendo com que o resto de calçamento após falha, que contribui sensivelmente para a medida, seja ignorado. Devido a isso e às outras razões mencionadas anteriormente, o programa não conseguiu ajustar adequadamente a resistividade anômala da falha, o que resultou em compensações nos outros blocos de maior sensibilidade: os superficiais.

Vale ressaltar aqui que, embora provenientes de um problema completamente diferente, o efeito na imagem de linha rasa, gerado pela penetração dos eletrodos no solo é praticamente idêntico ao que pode ser observado na camada superior da figura 6.

A segunda tentativa para melhorar o ajuste será modificar o método. $O$ damping factor normalmente atua restringindo apenas 0 tamanho da variação da resistividade, mas podemos fazê-lo atuar também diretamente sobre 0 valor da mesma. [Ellis and Oldenburg, 1994]. Entretanto essa modificação suaviza 
demais o resultado, como pode ser visto na figura 8 , e portanto não é adequada para o problema em questão.

A melhor maneira de resolver essa situação é informar previamente a resistividade dos blocos representativos da falha. Fazer um levantamento de anomalias superficiais óbvias é perfeitamente factível mesmo em uma aquisição real em campo. Estas informações são de incrível valia para um processamento adequado e não precisam ser exatas, uma boa estimativa basta.

Todos os ajustes até agora foram realizados com a norma padrão $I_{2}$, que tende a suavizar o modelo. Em alguns casos (nesse em especial) é preferível utilizar a norma $I_{1}$, também conhecida como inversão por blocos ou inversão robusta. Este algoritmo tende a criar grandes blocos com resistividade aproximadamente constante e portanto é mais adequado a casos onde há mudanças bruscas de resistividade (diques, objetos enterrados, etc) ou quando blocos de resistividade fixa são utilizados [Loke et al, 2003]. A figura 9 mostra o resultado obtido por esse método, já utilizando todas as otimizações sugeridas anteriormente.

Finalmente, a figura 10 mostra o resultado de um processamento feito utilizando um dado de melhor qualidade com o dobro de datum points (blocos estreitos e malha fina). Não foi preciso dar nenhuma informação prévia ou utilizar inversão robusta.

\section{Conclusões}

O acompanhamento cuidadoso do processo, o ajuste fino de parâmetros e a atenção para o surgimento de instabilidades são fundamentais para a obtenção de um resultado confiável. Mesmo um resultado com um baixo erro R.M.S pode estar contaminado por instabilidades computacionais ou efeitos de borda. Caso estes desvios coincidam com um bloco de alta sensibilidade, isso prejudicará toda a seção.

A maioria dos softwares de inversão utiliza como padrão um pequeno número de iterações, blocos largos e suavização imposta diretamente sobre os valores de resistividade; tudo isso para evitar o surgimento de instabilidades. Esta prática no entanto não fornece um resultado muito bom. Ao fazer um levantamento de anomalias superficiais e uma estimativa grossa das resistividades do terreno, um resultado muito mais preciso pode ser alcançado sem impor suavidade diretamente sobre o modelo.

Diferente de outrora, o custo em tempo computacional para se obter um resultado mais preciso é perfeitamente aceitável. O processamento mais pesado realizado neste trabalho demorou 1 minuto em um Pentium 4.

A figura 10 deixa claro que o principal fator para um bom imageamento elétrico é a qualidade dos dados adquiridos. Infelizmente nem sempre se tem essa qualidade de dados, e então um bom processamento pode fazer toda a diferença.

\section{Agradecimentos}

Este trabalho só foi possível devido ao incentivo e ao apoio prestado pela Brain Tecnologia Ltda.

\section{Referências}

Barker R.D., 1978. The offset system of electrical resistivity sounding and its use with a multicore cable. Geophysical Prospecting, 29, 128-143.

Dahlin T., 1996. 2D resistivity surveying for environmental and engineering applications. First Break, 14, 275-284.

deGroot-Hedlin, C. and Constable, S., 1990. Occam's inversion to generate smooth, twodimensional models from magnetotelluric data. Geophysics, 55, 1613-1624.

Dey A. and Morrison, H. F., 1979. Resistivity modeling for arbitrary shaped two-dimensional structures. Geophysical Prospecting 27, 106-136.

Ellis R.G. and Oldenburg D.W., 1994. Applied geophysical inversion. Geophysical Journal International 116, 5-11.

Griffiths D.H. and Barker R.D.,1993. Two-dimensional resistivity imaging and modelling in areas of complex geology. Journal of Applied Geophysics, 29, 211-226.

Lines L.R. and Treitel S. 1984. Tutorial : A review of leastsquares inversion and its application to geophysical problems. Geophysical Prospecting, 32, 159-186.

Loke M.H., 1994. The inversion of two-dimensional resistivity data. Unpubl. PhD thesis, Un. of Birmingham.

Loke M.H., Acworth I., Dahlin T., 2003. A comparison of smooth and blocky inversion methods in $2 \mathrm{~d}$ electrical imaging surveys. Exploration Geophysics 34, 182-187.

Loke M.H., 2004. Tutorial notes on $2 \mathrm{~d}$ and $3 \mathrm{~d}$ electrical imaging surveys. http://www.geoelectrical.com 


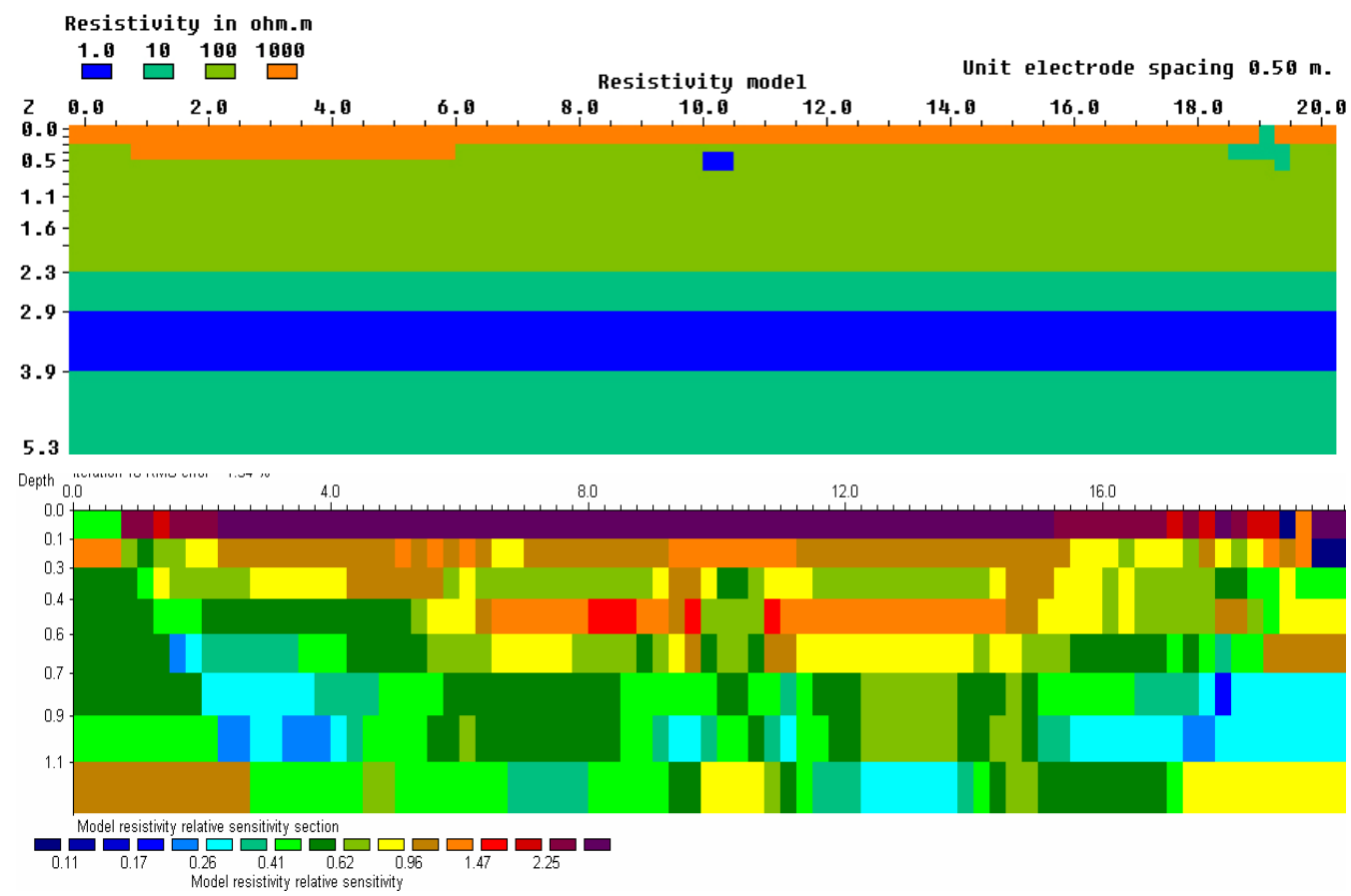

Figura1 - a) Modelo de resistividade do solo. A simulação foi gerada com 1\% de erro e protocolo dipolo-dipolo.

b)Sensibilidade relativa dos blocos do modelo para a resposta do potencial calculado após o processamento final.

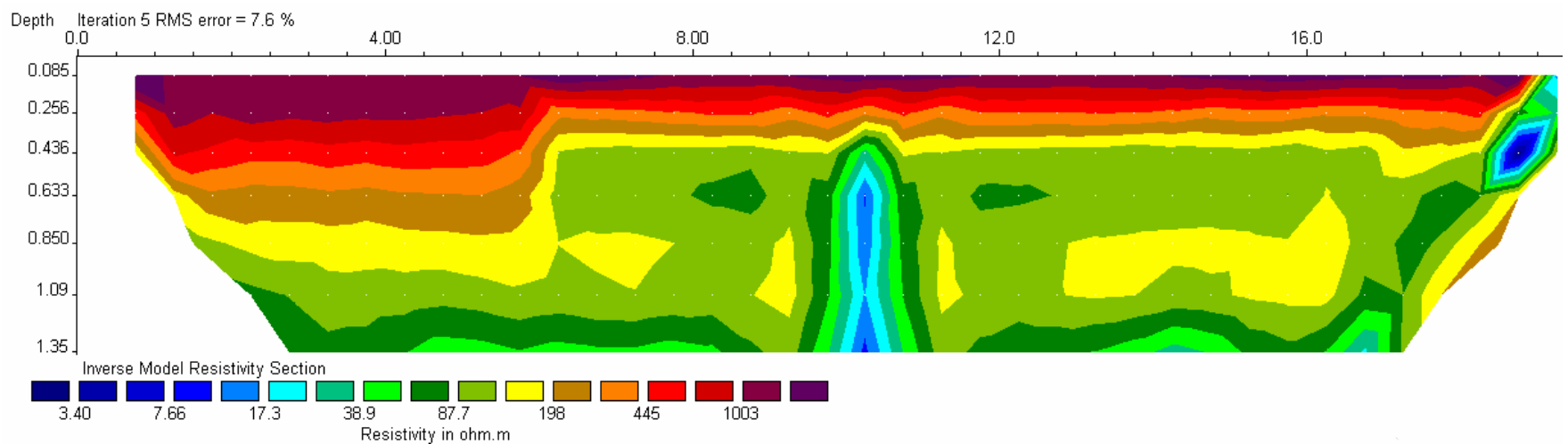

Figura 2 - Imagem de resistividade do modelo proposto, após a inversão com parâmetros em seus valores padrão.

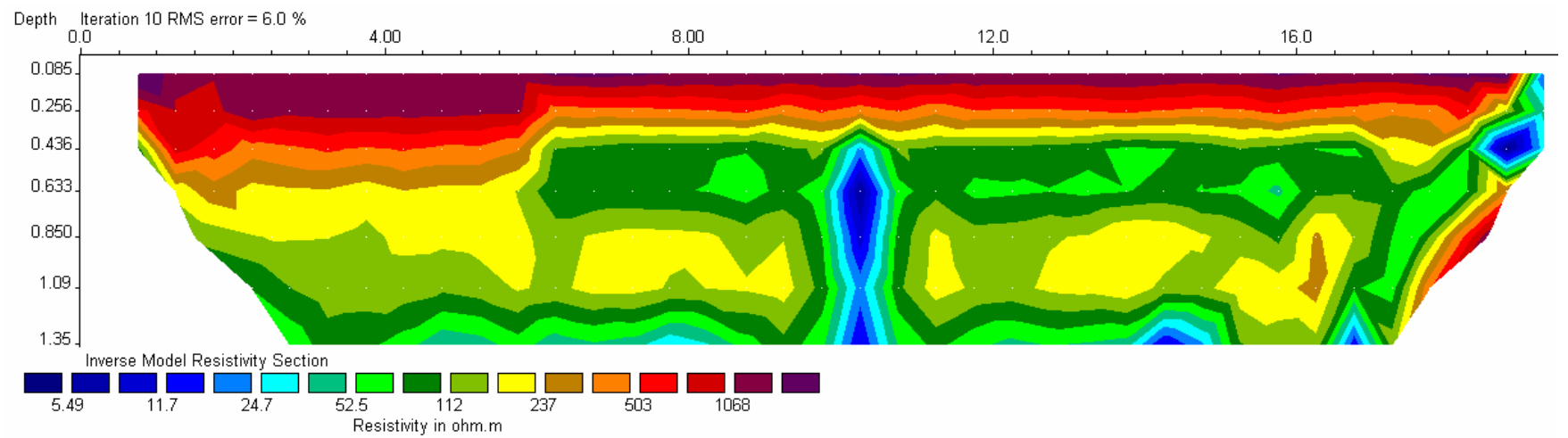

Figura 3 - Processamento original refeito com 10 iterações. 


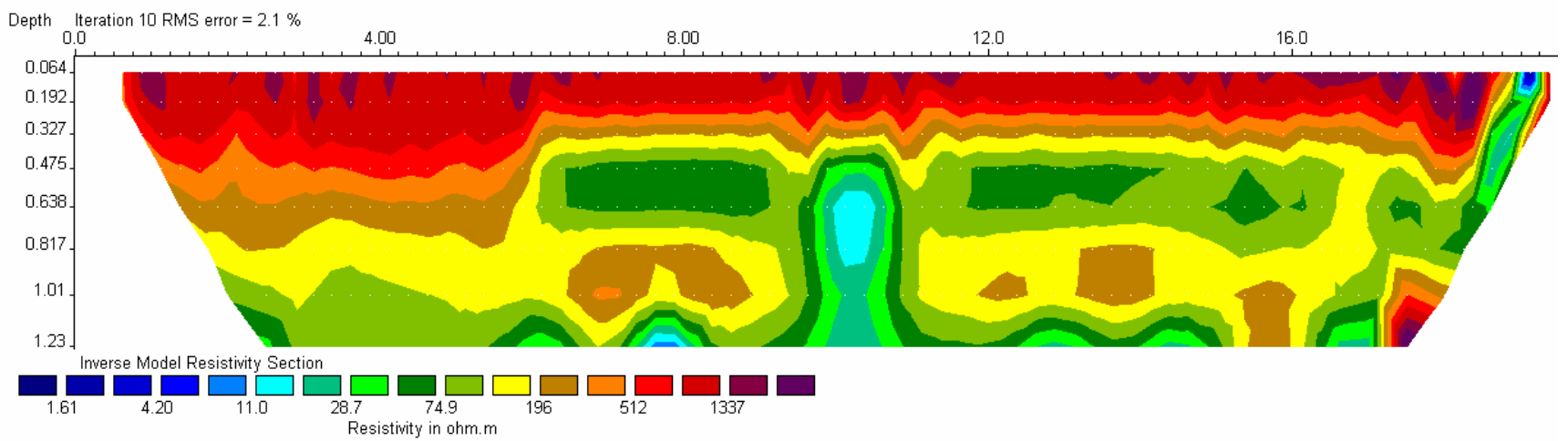

Figura 4 - Processamento original refeito com 10 iterações e blocos estreitos (tamanho igual à metade do espaçamento entre eletrodos)

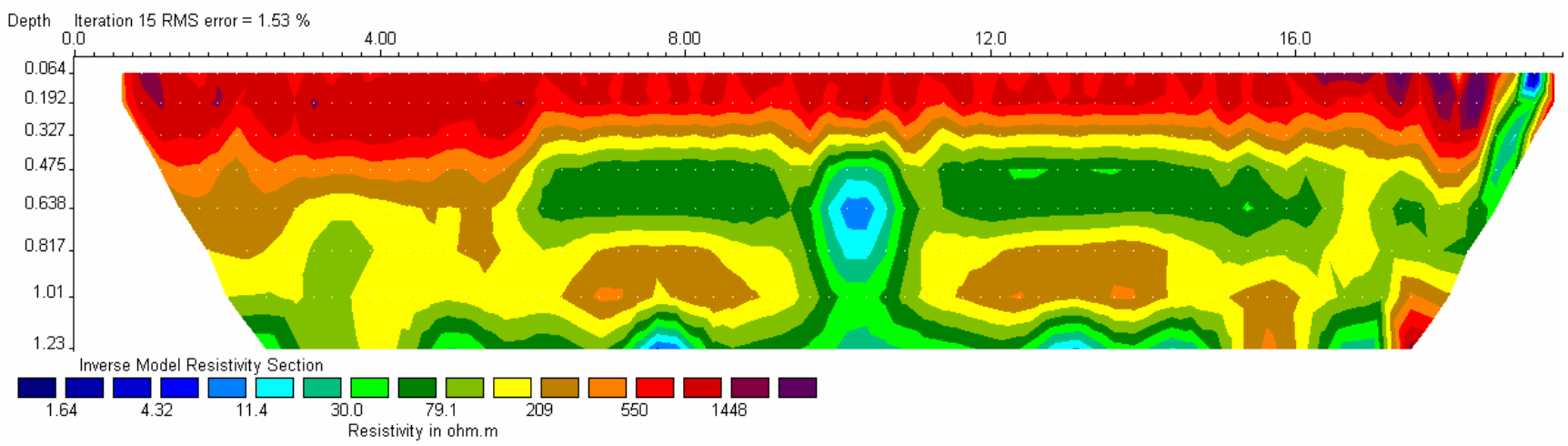

Figura 5 - Processamento original refeito com 15 iterações, blocos estreitos e malha duas vezes mais densa.

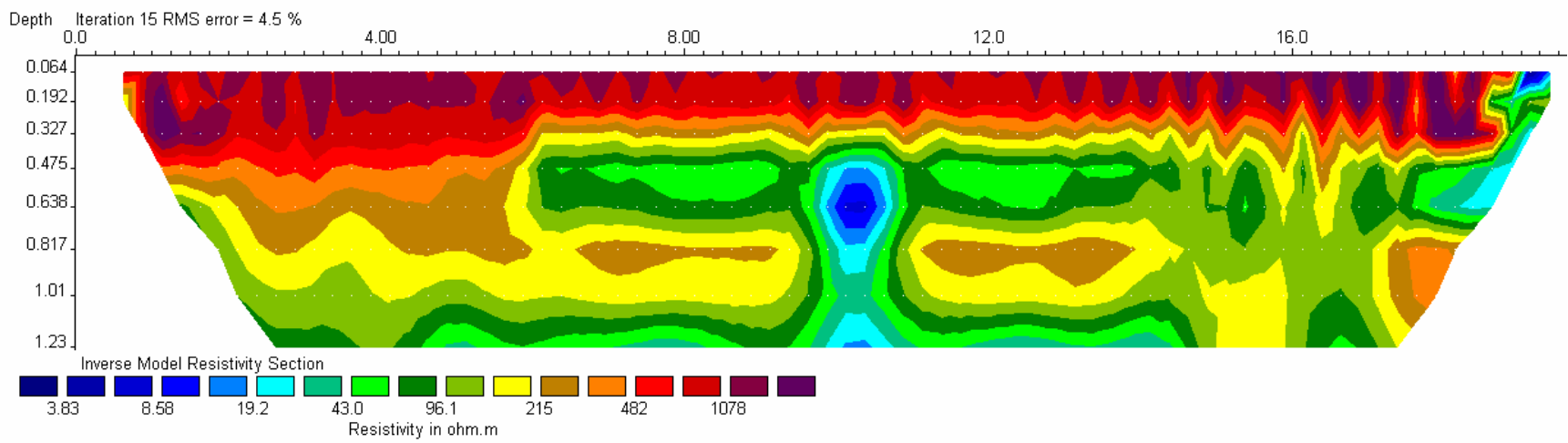

Figura 6 - Processamento original refeito com 15 iterações, blocos estreitos, malha fina, redução do efeito dos blocos laterais, limite de resistividade máxima e mínima, e otimização do damping factor. 


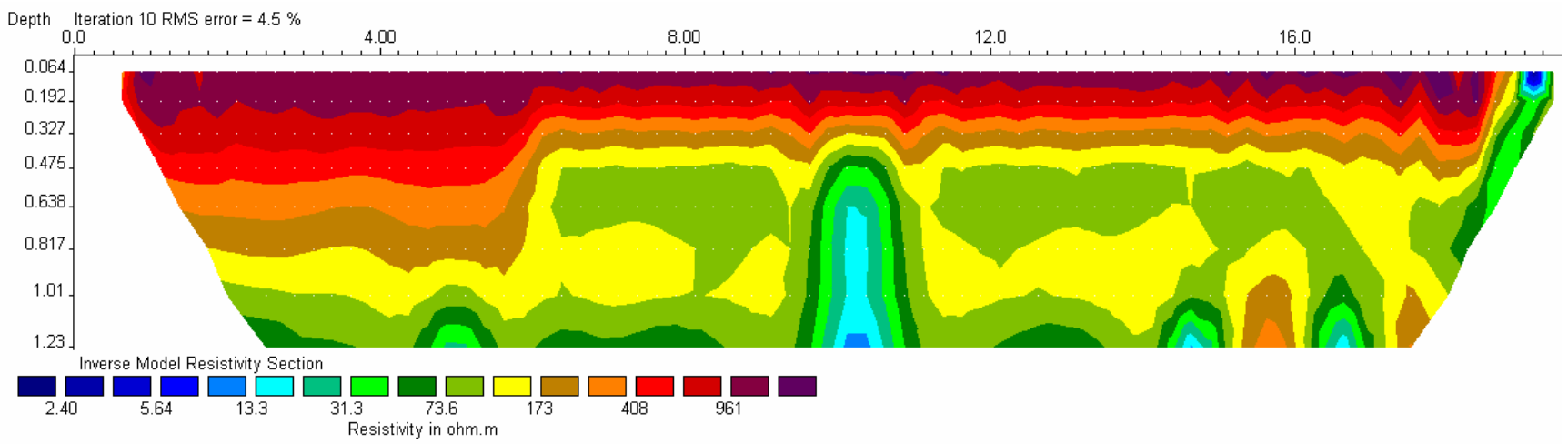

Figura 7 - Inversão realizada com suavização imposta diretamente sobre os valores de resistividade. Foram utilizados blocos estreitos, malha fina, limite de resistividade máxima e mínima e otimização do damping factor.

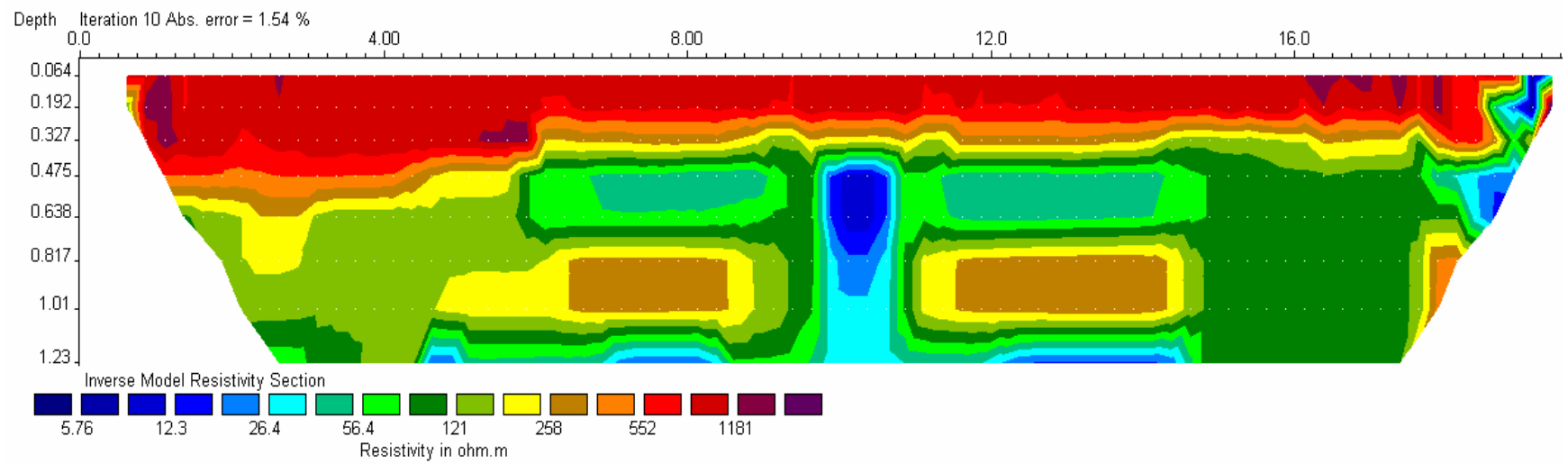

Figura 8 - Inversão realizada com o método robusto (norma $I_{2}$ ), blocos estreitos, malha fina, limite de resistividade máxima e mínima e otimização do damping factor. Os primeiros centímetros do calçamento e a falha tiveram suas resistividades previamente informadas.

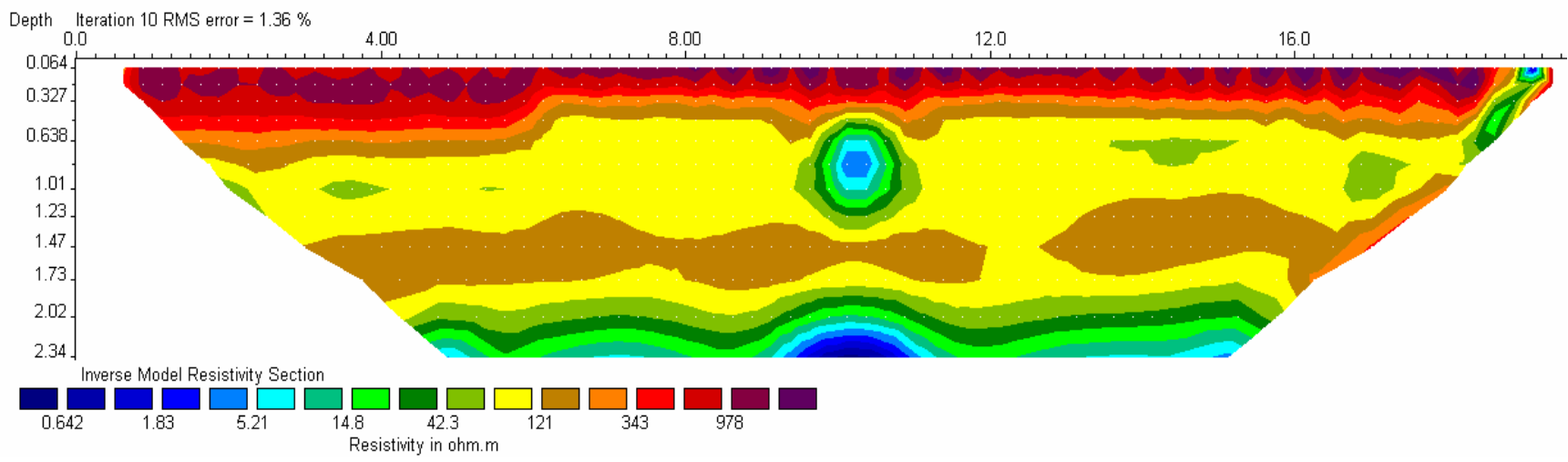

Figura 9 - Dados com o dobro de datum points. Processamento com blocos estreitos, malha fina, limite de resistividade máxima e otimização do damping factor. Não foi preciso dar informações prévias e nem modificar o algoritmo usado. 